\title{
Artículos
}

\section{¿Es ético canonizar la globalización?}

\author{
Francisco Javier Ibisate
}

\section{Resumen}

Este artículo analiza la etapa final del capitalismo, la globalización, en cuanto a sus beneficios para con la mayor parte de la humanidad. Cuestiona este proceso de mundialización cuyo principio es la exclusión de la mayoŕa. Explica cómo el neoliberalismo planifica la economía a partir del mercado mundial desde un cálculo económico que monetiza todos los valores humanos. Asume que una ideología y un modelo económico hay que juzgarlos por sus efectos humanos y, en este sentido, la inequidad, la miseria y la corrupción son los tres grandes motivos del descontenta general.

\section{Entre lo correcto y lo ético}

Es correcto hablar de mundialización por cuanto responde al proceso histórico del abatimiento de las fronteras nacionales por la mercancías, los flujos de capital, la avalancha tecnológica, los medios de comunicación social que nos informan al instante de todos los sucesos empresariales y nacionales en cualquier parcela del planeta. Es correcto hablar de mundialización por cuanto son las grandes multinacionales quienes globalizan este proceso histórico. Pero, ¿es ético canonizar la globalizacion? ¿Es ético aceptar un proceso de mundialización cuya génesis e inspiración dominante es la exclusión de la mayor parte de la humanidad? ¿Es ético un proceso de mundialización que abate, junto con las fronteras, las culturas y tradiciones nacionales? Este proceso de centralización, que es la mundialización, ¿no estará engendrando ya las fuerzas centrífugas que lo autodestruyan, lo mismo que acaba de suceder a los centralistas socialismos reales del este europeo? Sobre todo, si el liberalismo de mercado del siglo XIX no fue la adecuada respuesta, ni económica ni ética, ¿cómo y por qué la etapa final del capitalismo, la globalización, podrá ser la adecuada solución, si el neoliberalismo se asienta en las mismas fuerzas motrices, que profundizan aún más el poder de la minoría y la exclusión de la mayoría de la humanidad? Se integran dos interrogantes: sus principios éticos y su supervivencia histórica. 
Hay dos razones históricas para plantear ambas interrogantes. Uno de los argumentos para proclamar al neoliberalismo como el fin de la historia es la descomposición política y económica de los socialismos reales. Este es un mal argumento o un argumento mal usado, y queremos advertir de este error a los creyentes del neoliberalismo. Los socialismos reales no se descompusieron por ser socialistas, que nunca lo fueron, sino por ser ideológica, política y económicamente ultracentralistas, verticalistas y autoritarios, es decir, no socialistas y no democráticos. En otras palabras, por haber instaurado una nueva modalidad de imperio, cada vez más intolerable en un siglo $\mathrm{XX}$ (ECA, 1996, p. 570). Toda la autocrítica de los supervivientes de los socialismos reales se centra en el rechazo a su centralismo, al imperio de una minoría dominante. El neoliberalismo globalizante y los socialismos reales son dos modalidades de imperios centrales, donde varía la forma de ejercer el efecto dominación.

Los socialismos reales utilizaron la planificación, no económica, sino militarista (socialismo de cuartel) de ordeno y mando, con énfasis en la cantidad más que en la calidad, sin mayor consideración al cálculo económico y a la participación creativa de las clases trabajadoras. El neoliberalismo monta la planificación de la economía desde el mercado mundial, desde la ultracalidad tecnológica sin cercana referencia a las necesidades mayoritarias, desde un cálculo económico que monetiza todos los valores humanos (la moneda es el álgebra del valor), desde una bolsa de valores que perturba a los mismos sectores productivos, desde una idolatría del mercado que no acepta regulaciones financieras, laborales o administrativas. Por distintas vías llegamos a similar planificación centralista.

EI neoliberalismo ciertamente es atractivo y hasta convincente porque utiliza elementos universales y seculares. El mercado existe desde el tiempo de los fenicios, y las ferias del medioevo eran el lugar de encuentro e intercambio de culturas y mercancías; también el mercado del barrio es un lugar para hacer amistades y servicios. Los avan- ces de la tecnología, los inventos y las innovaciones, han solventado históricamente el dilema de las necesidades crecientes y los recursos relativamente escasos, han mejorado la calidad de los productos, de la salud y de la esperanza de vida e, incluso, el tiempo de ocio de las clases trabajadoras. La moneda y el sistema bancario, tan antiguos como los templos más antiguos que eran bancos, han hecho posible el intercambio comercial y el crédito productivo. La iniciativa y el interés personal, así como la legítima propiedad privada son valores corrientes que los padres inculcan a sus hijos. La competitividad, si es competencia por calidad, beneficia al usuario y al consumidor. Y así, en el neoliberalismo podemos encontrar una serie de valores seculares, inicialmente buenos, que lo hacen atractivo y convincente. Dudar de la ética del liberalismo no es atacar los grandes principios económicos, presentes en todas las economías, admitiendo que los socialismos reales conculcaron algunas de estas normas universales.

La duda ética y económica sobre el neoliberalismo se fundamenta en la historia del siglo XX. Todos los valores citados y otros más son inicialmente buenos y universales. Sin embargo, en manos del liberalismo de mercado no resolvieron ni el problema económico ni el fin ético de toda economía. A los neoliberales les gusta olvidar las crisis, en plural, de los treinta y las más recientes sacudidas de 1970 a nuestros días, que no son obra de los socialismos reales. A los neoliberales no les gusta recordar que el Estado de bienestar los salvó de su total naufragio en Europa occidental luego de la segunda guerra mundial, pero acumulan todas sus críticas para responsabilizarlo de la crisis iniciada en 1970. Sin embargo, los estados de bienestar se levantan hoy como la gran crítica histórica al neoliberalismo, porque ellos lograron conjugar el crecimiento económico con una distribución más equitativa y con el desarrollo de la seguridad social. Los estados de bienestar trataron de historizar en el siglo XX la célebre divisa de la revolución francesa (1789): libertad, igualdad y fraternidad, entendida como solidaridad (ECA, 1996, p. 865). 
La solidaridad es un término ausente en el diccionario neoliberal, como nos to ha recordado la cumbre de Conpenhague (1995), que unifica la insolidaridad social con la pobreza y el desempleo generalizados. Es normal que a nivel de continente latinoamericano el neoliberalismo, como concepto y como realidad, no se presente como el modelo ético que lleve a la liberación. No tendría sentido reflexionar sobre términos y conceptos generales si los dirigentes de nuestro país y región no obedecieran, con fe religiosa, el decálogo de las instituciones y empresas internacionales.

\section{La Rerum Novarum dos}

En 1991 celebramos el centésimo aniversario de la gran encíclica de León XIII. Dos años antes se había vitoreado la caída del muro de Berlín, y en diciembre de 1991 se firmaba el acuerdo de Minsk, que ponía fin a la Unión de Repúblicas Socialistas Soviéticas, al bloque y al pacto de Varsovia. Se desvanecía uno de los "fantasmas" que había perturbado el sueño de León XIII; pero Juan Pablo II advertía que la caída del comunismo (a la que el Papa polaco había contribuido) no significaba la adhesión a un capitalismo, calificado de primitivo y salvaje. Digamos que el siglo $\mathrm{XX}$ dio razón a muchos de los temores de León XIII porque, por una parte el comunismo -en su modalidad de socialismos reales - ha demostrado no ser la solución y, por otra parte, los estados de bienestar y la economía social de mercado, a la alemana, limaron por un tiempo las aristas hirientes del capitalismo primitivo. Ahora, al terminar el siglo $y$, como dicen, al entrar en el tercer milenio, necesitamos una Rerum Novarum dos. De hecho, esta encíclica ya se está escribiendo entre muchos, y por ello resulta más universal.

\section{1. "Cercano el tercer milenio"}

El mismo Juan Pablo II redactó hace tres años una carta apostólica, "Cercano el tercer milenio", y no lo ve con color de rosa. A los papas les aflije el problema del ateísmo; pero ahora no es el ateísmo comunista que persigue a la "Iglesia del silencio", sino el ateísmo "mundializado", que ni afirma ni niega, sino simplemente prescinde y no necesita para nada de Dios. Se trata de la ausencia de Dios, de la indiferencia religiosa y del relativismo ético. Se trata de la "crisis de civilización que se ha ido manifestando sobre todo en el occidente tecnológicamente más desarrollado, pero interior-

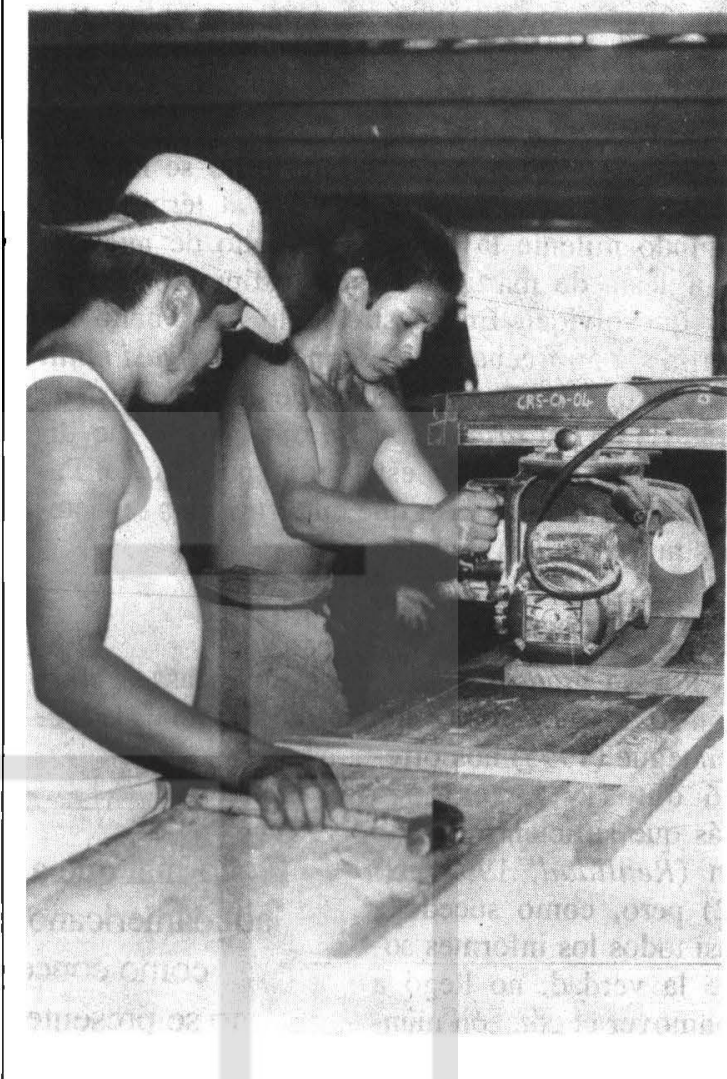

mente empobrecido por el olvido y la marginación de Dios" $\left(\mathrm{N}^{\circ} 52\right)$. Y añade que "A la crisis de civilización hay que responder con la civilización del amor, fundada sobre los valores universales de la paz, solidaridad, justicia y libertad, que encuentran en Cristo su plena realización" $\left(\mathrm{N}^{\circ} 52\right)$.

Donde está ausente Dios, no casual sino causalmente, suele estar ausente la mayoría de la humanidad."Recordando que Jesús vino a evangelizar a los pobres (Mt 11, 5; Lc 7, 22), ¿cómo no subrayar más decididamente la opción preferencial de la Iglesia por los pobres y marginados? Se debe decir ante todo que el compromiso por la justicia y por la paz en un mundo como el nuestro, marcado por tantos conflictos y por intolerables desigualdades sociales y económicas, es un aspecto sobresaliente de la preparación y celebración del jubileo" $\left(\mathrm{N}^{\circ}\right.$ 51). Traduciendo la doctrina en buenas obras, el Papa propone una acción globalizante:"Así, en el espíritu del libro del Levítico (25, 8-28), los cristianos deberán hacerse voz de todos los pobres del mundo, proponiendo el jubileo 
como un tiempo oportuno para pensar, entre otras cosas, en una notable reducción, si no en una total condonación, de la deuda internacional, que grava sobre el destino de muchas naciones" $\left(N^{\circ} 51\right)$. Como esta presencia de la Iglesia no se hace de gratis, el Papa nos recuerda que "al término del segundo milenio la Iglesia ha vuelto de nuevo a ser Iglesia de mártires. Es un testimonio que no hay que olvidar. En nuestro siglo han vuelto los mártires, con frecuencia desconocidos, quasi militi ignoti (soldados desconocidos) de la gran causa de Dios"'( $\mathrm{N}^{\circ}$ 37)(Carta a las Iglesias; 16-31 de diciembre de 1996). Con esta carta apostólica el Papa da lineamientos para que entre muchos redactemos la Rerum Novarum dos.

\subsection{Otros documentos}

Por su gran convocatoria y su escasa aceptación de los poderosos, la cumbre mundial de Copenhague (1995) nos ofreció datos y reflexiones más que suficientes a este fin (Realidad, 1994, $\mathrm{N}^{\circ}$ 42) pero, como sucede a casi todos los informes sobre la verdad, no llegó a conmover el corazón mundial (ECA,1996, p. 581). Tanto en Europa como en América Latina se han realizado una serie de se-

Es normal que a nivel de continente latinoamericano, el neoliberalismo, como concepto y realidad, no se presente como el modelo ético que lleve a la liberación. cuentemente los comentarios estropean el texto original. Hay con todo un dato relevante, que confirma las conclusiones de otros análisis científicos: los dieciocho superiores regionales (desde México hasta Chile) y sus asesores afirman que "en la década de los ochenta, el proceso de ajuste, necesario para reorganizar las economías, superar el déficit fiscal y de balanza de pagos, pagar la deuda y recuperar el crecimiento, golpeó tremendamente a las mayorías populares de todos nuestros países. Después, en los años noventa, al madurar el ajuste y la apertura, se esperaba que los tiempos difíciles concluyeran. Pero encontramos que no ha sido así, a pesar de que efectivamente se ha dado un crecimiento económico moderado. Hay un sentimiento muy generalizado en los sectores populares y pobres de pérdida de la calidad de vida y evidencias contundentes del deterioro en la distribución del ingresos... La inequidad, la miseria y la corrupción, que son los tres grandes motivos de descontento general, están presentes y en no pocos aspectos se han agravado". Sobra decir que El Salvador es un caso típico de esta tesis general, que nuestros gobernantes $y$ sus comités económicos no logran sensibilizar.

En la carta introductoria, al presentar el documento, dicen que, desde su misión de servicio a la fe y a la justicia, desean compartir algunas reflexiones sobre el llamado neoliberalismo en nuestros países". Nos resistimos a aceptar tranquilamente que las medidas económicas aplicadas en los últimos años, en todos los países latinoamericanos y el Caribe, sean la única manera posible de orientar las economías y que el empobrecimiento de millones de latinoamericanos sea un costo irremediable de un futuro crecimiento. Detrás de estas medidas económicas existe una estrategia política, subyace una concepción de la persona humana y una cultura que es necesario discernir desde nuestros propios modelos de sociedad a la que aspiramos y por la cual trabajamos al lado de tantos hombres y mujeres, movidos por la esperanza de vivir y dejar a las futuras generaciones una sociedad más justa y humana". 
Estos superiores religiosos se expresan como ciudadanos latinoamericanos y como ciudadanos del reino de Dios; desde ambas ciudadanías brotan las reflexiones, la inconformidad y las sugerencias de algo nuevo: la utopía, lo que no existe, pero que es la norma de lo que debe existir. "Las consideraciones presentadas no pretenden ser el análisis científico de un asunto complejo que requiere investigación desde muchas disciplinas. Son solamente reflexiones, que encontramos pertinentes, sobre las consecuencias y criterios del neoliberalismo y las características de la sociedad que anhelamos. Nuestra preocupación principal al compartir estas reflexiones es de orden ético y religioso. Los comportamientos económicos y políticos a los que nos referimos reflejan en el ámbito de lo público los límites y contravalores de una cultura fundada en una concepción de la persona y de sociedad humana ajena al ideal cristiano".

Una vez leído todo el documento parece conveniente agregar un comentario interpretativo de esta introducción. Es cierto que una docena de páginas "no pretenden ser el análisis científico de un asunto complejo". Pero también es cierto que, sin pretenderlo, lo que tenemos delante sí es un compendio de análisis científico, por cierto fruto de una larga investigación de profesores universitarios, centros de investigación, teólogos y pastoralistas cercanos a la comunidad. Por lo tanto, las reflexiones y sugerencias que se desean "compartir" no son elucubraciones gestadas en el vacío o desde el interior de una sacristía. La novedad de este tex to (y otros similares), que los diferencia de la mayoría de informes gubernamentales e internacionales, es que "nuestra preocupación principal es de orden ético y religioso". Como se repetirá más adelante, la oposición al neoliberalismo no significa rechazar o menospreciar la ciencia económica, sus políticas y mecanismos de funcionamiento, sino negarse a aceptar el totalitarismo economicista que somete toda la vida humana a las fuerzas del mercado. A una ideología y modelo económicos hay que juzgarlos por sus efectos humanos; sin ello no es economía.

Dos líneas del texto dan lugar a un breve paréntesis."La inequidad, la miseria y la corrupción, que son los tres grandes motivos del descontento general, están presentes y en no pocos aspectos se han agravado". La afirmación se refiere al continente latinoamericano, pero la realidad es más amplia. Por estar humana y académicamente

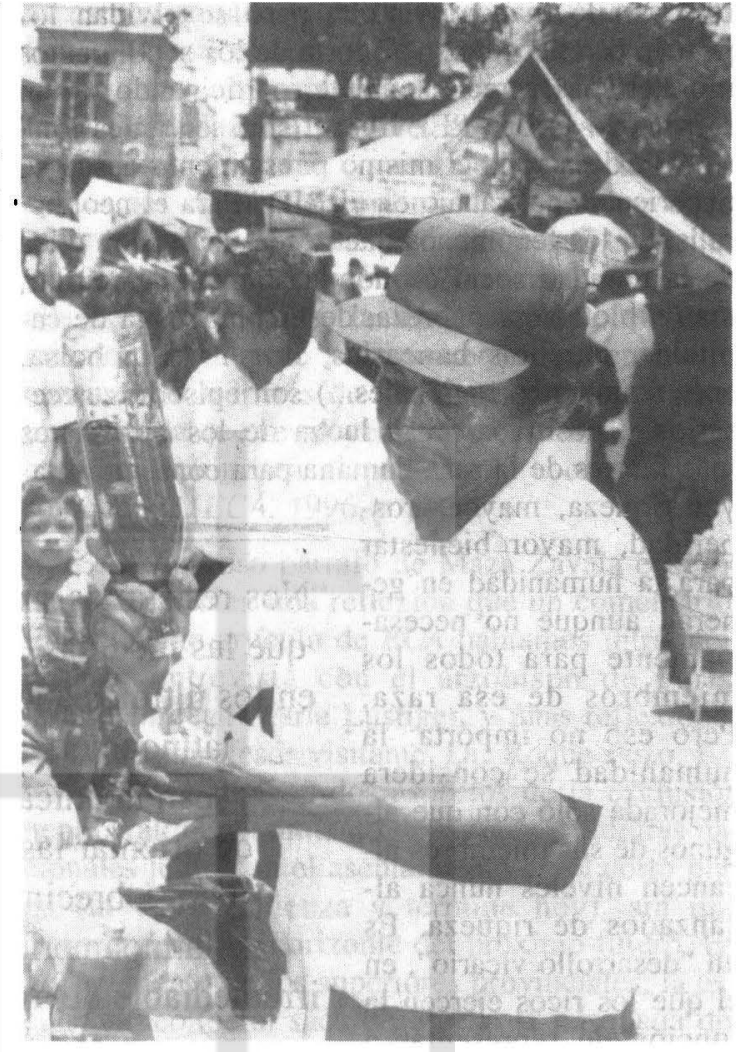

interesado en la evolución de las economías del este europeo, valga recordar que las instituciones financieras internacionales y el G-7 impusieron a estos países las mismas recetas del ajuste estructural, especialmente a la antigua Unión de Repúblicas Socialistas Soviéticas, hoy Rusia (plan G.Yaulinsky, 1991). Sin detallar los resultados económicos recesivos, los analistas residentes y extranjeros de la actual Rusia coinciden en que "la inequidad, la miseria y la corrupción están presentes y en no pocos aspectos se han agravado" $(E C A, 1996$, p. 571). Algo muy serio y preocupante se esconde en la mundialización del neoliberalismo.

\subsection{Neo-liberalismo: no-liberalismo, sino ex- clusión}

En 1989, Luis de Sebastián titulaba así un artículo:"El neoliberalismo una negación del liberalismo" (Realidad Económica y Social, 1989, p. 419), y lo presentaba como un darwinismo social. De Adam Smith se suele recordar su breve refe- 
rencia a la mano invisible, pero se olvidan los principios éticos de su "Teoría de los sentimientos morales". Más recientemente, participando en un seminario sobre "El liberalismo en cuestión" (1993), desarrolla el mismo pensamiento desde su experiencia de trabajo en el BID:"Para el neoliberalismo, los fenómenos que desde una visión ética de la realidad socio económica llamamos conflictos (explotación, pobreza, desempleo, fuga de capitales, quiebras bancarias, crash de la bolsa, enfrentamientos regionales...) son episodios necesarios y positivos de la lucha de los ejemplares más fuertes de la raza humana para conseguir mayor riqueza, mayor prosperidad, mayor bienestar para la humanidad en general, aunque no necesariamente para todos los miembros de esa raza. Pero eso no importa: la humanidad se considera mejorada sólo con que algunos de sus miembros alcancen niveles nunca alcanzados de riqueza. Es un "desarrollo vicario", en el que los ricos ejercen la función de representar a toda la humanidad en el

"Nos resistimos a aceptar tranquilamente
que las medidas económicas aplicadas
en los últimos años, en todos los países
latinoamericanos y el Caribe,
sean la única manera posible
de orientar las economías y que
el empobrecimiento de millones
de latinoamericanos sea un costo
irremediable de un futuro crecimiento".

"Nos resistimos a aceptar tranquilamente que las medidas económicas aplicadas latinoamericanos y el Caribe, sean la única manera posible de orientar las economías y que el empobrecimiento de millones de latinoamericanos sea un costo riales de la creación". disfrute de los bienes materiales de la creación". Estas palabras servían de introducción al seminario organizado por Cristianisme i Justicia ( $E C A$, 1996, p. 67).

Desde una perspectiva mundial, la cumbre de Copenhague, al ejemplarizar el tema de la insolidaridad social, afirma que:"menos del 10 por ciento de la población total del mundo participa plenamente en las instituciones políticas, económicas, sociales y culturales que conforman sus vidas". Y como una consecuencia para nuestros países agregan que: "El poder político sigue estando centralizado, sobre todo en el mundo subdesarrollado, donde - como promedio- menos del 10 por ciento de los gastos nacionales se asigna a los gobiernos locales" (Realidad, 1994, p. 857).

Las estadísticas traducen un fenómeno secular, es decir, gestado a lo largo del siglo $\mathrm{XX}$ con la separación y confrontación de países desarrollados y subdesarrollados. La confrontación no se centra sólo en los crecimientos desiguales del PIB, sino en las relaciones y fuerzas asimétricas para asegu- rar dicho crecimiento. Basta un ejemplo: cuando en la década de 1970 se ofrece la oportunidad de abrir la puerta al desarrollo gracias al reciclaje de los petrodólares, por inexperiencia administrativa y mala gestión de muchos gobiernos, se cierra la década con el gravamen de la impagable deuda externa que, a modo de esposas financieras, los amarran a aceptar los condicionamientos de los grandes acreedores, de acuerdo con el principio: si deben, deben pagar. Un siglo que comienza con la colonización política, termina en la colonización inanciera. Las mayorías populares fueron excluidas de la toma de decisiones gubernamentales, pero se las incluye en primera fila al sobrellevar las peores consecuencias de tales decisiones. Los pobres poco o nunca se benefician en las fases del auge $y$ siempre aumenta el desempleo y la pobreza en las recesiones económicas. Da pena repetir que la teoría del rebalse nunca juega espontáneamente. $Y$ da pena repetir que esta misma teoría es parte integrante de la exclusión neoliberal:a los pobres y desempleados "les tocará crecer mañana". Al desarrollo "vicario" se une el desarrollo "apocalíptico", al final de los tiempos.

A partir del amarre de la deuda externa y la dependencia financiera, la exclusión neoliberal abate otros componentes nacionales. La tecnología y el mercado internacional reducen las defensas de las fronteras nacionales. En virtud de una teoría, no siempre comprobada, convencen a los estados de que son deficientes, y con frecuencia los gobiernos suelen demostrarlo:"El Estado depredador" de Moisés Naím (ECA, 1996, p. 884). Con pretexto de concentrarse en la inversión social, se reduce ésta al reducirse el papel del Estado; se reduce tanto que las elecciones presidenciales dejarán ya de tener sentido. Al Estado le queda la función de "subsidiaridad", pero con la privatización de los servicios públicos rentables se le agotarán las fuentes de financiamiento de la subsidiaridad. Ahora, la creciente deuda externa cierra el círculo vicioso de la dependencia: los ricos se endeudan para ganar (dólares); los pobres se endeudan para 
pagar, y la dependencia se traduce en exclusión.

\subsection{La etapa superior del capitalismo}

Maza Zavala sintetiza vigorosamente esta exclusión de los componentes nacionales, al describir la "etapa superior del capitalismo". Desde luego esto es un nuevo ropaje ideológico de la dominación, corresponde a una nueva etapa del desarrollo capitalista en el mundo, que es la etapa de la globalización; la etapa superior del desarrollo capitalista recibe el nombre de globalización. Este desarrollo, como sabemos, ha atravesado por varias etapas: la etapa del desarrollo nacional, la etapa de la internacionalización (la economía de las naciones), la etapa de la transnacionalización (las grandes estructuras más allá de las fronteras nacionales) y ahora la etapa de la globalización, es decir, el mundo como un espacio abierlo, el mundo como una totalidad, el mundo como el escenario para un juego estratégico en el cual se abstraen las fronteras, se abstraen los intereses nacionales, y todo se constituye en el juego de las grandes fuerzas del mercado mundial. Esta es la etapa que corresponde al neoliberalismo: abatir las fronteras nacionales. Proteccionismo, no; preferencia al mercado interno, no; planificación nacional, no; regulación de la inversión extranjera, no; soberanía monetaria nacional, no. Apertura, abatimiento de cualquier obstáculo para la movilización de factores, mercancías, capitales, adscripción incondicional a los cambios emergentes de los centros mundiales de desarrollo, totalización del juego estratégico. Esta es la etapa de la globalización.

Una vez más, la globalización no solamente significa homogeneización del modo de producción en el mundo, sino también uniformidad cultural. Los patrones de comportamiento, los valores, las necesidades, los gustos, los hábitos, todo se mundializa; ya no hay lugar para los valores tradicionales, para los valores que identifican a un pueblo, los valores en que se fundamenta la existencia de una nación, sino que hay lugar para la universalización; pero una universalización que no resulta del consenso, que no resulta de la confluencia de las voluntades de las diferentes sociedades humanas, sino que resulta de un designio, de una matriz diseñada para que se ajusten a ella, a su funcionamiento, todas las actividades. Y de allí que haya, por consiguiente, un sistema mundial de información, un sistema mundial de comunicación, un sistema mundial de recreación, un sistema mundial de estilos de vida y, desde luego, un sistema político ,mundial: el sistema de la democracia representativa, una manera mundial de entender y aceptar la actividad del hombre, el hombre sin transcendencia, el hombre como sujeto y objeto de las apetencias de la vida ordinaria, el hombre en el afán de lucro y disfrute, el hombre que encuentra en ello el principio y fin de su razón de ser; más allá del pensamiento, la transcendencia, el sentimiento, el valor de permanecer, el de crear una continuidad a través de las generaciones, el tener una historia que se proyecta hacia el futuro. No. El hombre termina en el presente y a eso estamos sometidos...(ECA, 1996, p. 585).

Este vigoroso párrafo de Maza Zavala está pidiendo más bien una reflexión que un comentario. En el mismo artículo de ECA habíamos introducido una entrevista con el arzobispo de París, monseñor Jean Marie Lustiger, y unas reflexiones de nuestro profesor visitante, Dr. Roque Pozo. Estos autores subrayan dos aspectos de la exclusión neoliberal: el abatimiento de valores y culturas nacionales junto con el asentamiento en el corto plazo (la vida comienza y termina hoy), sin una transcendencia y horizonte del próximo futuro. En el documento de los superiores provinciales, la exclusión neoliberal saca de escena la búsqueda del "bien común". "En un contexto donde desaparece el horizonte del bien común y cada uno busca su propio provecho en el mercado, la exclusión social se profundiza".

La exclusión neoliberal avanza nacionalmente porque un Estado excluido se convierte en un gobierno excluyente. Nuestro gobierno y su ambigüo comité económico son un ejemplo representativo: es el gobierno del diálogo que no escucha a nadie. Nunca como en el año de 1996 se habían presentado tantas propuestas y programas de reconversión económica desde diferentes sectores nacionales: Asociación Nacional de la Empresa Privada, Fundación para el Desarrollo, Comité Permanente del Debate Nacional,FMNL..., invitando a un diálogo nacional abierto. Se les oyó, pero no se les escuchó. Las grandes normativas vienen desde fuera. En 1995 íbamos a ser Taiwán, Hongkong, Singapur, Argentina: maquilas con dolarización. En 1996, privatización con multinacionales (más el IVA) y en 1997, clusters con inversión extranjera. Se afirma que existe en el país una imaginación y una capacidad productiva subyacente en el sector empresarial, pero se excluye la imaginación 
y la productividad en la gestación de propuestas de reestructuración económica y social. Incluso las doce medidas sugeridas e intercaladas en el discurso presidencial del 1 de junio, esperan una sensible aplicación. Con ello, los mismos sectores empresariales sienten que están excluidos y pierden su credibilidad en el gobierno. Si los aportes y programas nacionales se cotizan menos que las asesorías de Washington, se hace difícil contrarrestar la exclusión neoliberal. Tal vez sea cierto que el mayor enemigo del Estado suele ser el gobierno. El "cambiar para mejorar" necesita otro estilo de Estado y de gobierno.

\section{3. ¿La dictadura del empresariado?}

El ingeniero y economista Héctor Dada, en un ameno y agudo artículo, se pregunta si - dejada atrás la "dictadura del proletariado"- no estamos realmente sometidos a la ¿"dictadura del empresariado"? Ni en broma, ni en serio, sino todo lo contrario, Héctor Dada establece una comparación entre ambas dictaduras, que ilumina bastante nuestra exclusión nacional. Dado que este ingenioso artículo apareció en un diario de menor circulación conviene difundirlo en onda más larga.

Ahora es el empresariado la clase productiva por excelencia, la que debe conducir el proceso que nos liberará de las lacras del subdesarrollo y de la pobreza... Hoy el gran objetivo de los segundos (el empresariado) es la revolución productiva a escala mundial, identificada como 'globalización', y son los empresarios los encargados principales de la integración de lo 'nacional' en ese gran movimiento de liberación universal, con el respaldo de instrumentos planetarios como el Banco Mundial y el Fondo Monetario Internacional y - por sobre todo- el capital transnacional. Las dos dictaduras "comparten un gran rechazo del aparato del Estado... Para los pontífices actuales, supuestos seguidores de Adam Smith, el aparato del Estado debe ser minimizado, si no eliminado, dado que se le atribuyen contradicciones insuperables con el mercado -instrumento del empresariado para liberar las fuerzas productivas - así como con la sociedad...

De la misma manera que la revolución proletaria sería conducida por la 'vanguardia del proletariado', un grupo de lúcidos intérpretes de sus intereses, así 'los profetas de hoy también afirman que tienen que enfrentar un serio problema para lograr su hegemonía de clase: el empresariado está alienado por decenios de mercantilismo... Para ellos también una autoproclamada vanguardia, esta vez del empresariado, fiel intérprete de los intereses de clase que pretenden representar (pese a que nadie les ha concedido la representación), es la que tiene que asumir la tarea de definir las reglas del juego y los caminos a transitar en el proceso de la liberación globalizadora, a partir del reconocimiento de un pretendido carácter ontológico del mercado, y con mecanismos de decisión similares al centralismo democrático... Hoy la vanguardia parece integrada por pequeños burgueses tecnocratizados (los estadounidenses les llaman 'tecnopols') y unos cuantos empresarios. ¿No es esto, nos preguntamos, una suerte de 'dictadura del empresariado', en la que en forma similar a la del proletariado, la clase que se supone beneficiaria no tiene en cuanto tal mayores espacios de participación en las decisiones que la afectan?

En caso de dar una respuesta afirmativa a esa interrogante ¿no estaría también ligada a prácticas de exclusión de los sectores pertenecientes a otras clases y aún de aquellos que perteneciendo a la supuesta clase hegemónica no son considerados con la capacidad de asumir liderazgos adecuados en la construcción de la dominación del mercado? ¿Podemos extrañarnos entonces que la economía se maneje en sigilo, como lo afirmó un ministro, que las decisiones se impongan sin discusión y a veces atropellando la institucionalidad, los procedimientos y la legalidad? ¡Los lúcidos miembros de ta vanguardia no pueden permitir que los alienados y los creyentes en el pasado interfieran en su marcha triunfal hacia el futuro, así ellos mismos cambien de rumbo con frecuencia y sin explicación! Ellos se han atribuido a sí mismos el derecho y el deber de definir qué hacer $-\mathrm{y}$ cómo, cuándo y dónde hacerlo- decidir de los bienes del Estado y de la política como su propio coto de caza en el que nadie, salvo los elegidos por la historia, puede participar. Nos interrogamos entonces si en esta visión los espacios de la participación no sirven sólo para legitimar lo decidido, y no para participar en la decisión; al fin y al cabo, afiman, ésta debe decidirse 'técnicamente', no en base a criterios políticos.

¿Esta 'vanguardia del empresariado', como la del proletariado ayer, puede tener resultados negativos para la clase de la cual se han autodeterminado defensores? Si los sacrificios, a nombre de la construcción revolucionaria, beneficiaron en no 
pocos casos a la nomenklatura, a un pequeño grupo que controlaba el partido y el aparato del Estado, ¿no será que algo similar está sucediendo en aquellos lugares, cada vez más numerosos, en donde las nuevas teorías y prácticas mesiánicas se han impuesto? ¿No es cierto que el pequeño grupo que controla la definición de la política económica (directamente o por intermediarios), legitimado más desde el exterior que desde el interior, es el que se convierte en el beneficiario prioritario, en tanto otros sectores empresariales se ven afectados en el proceso, excluidos en la definición de la política y de sus resultados positivos? ¡Y no digamos los otros grupos sociales que deben esperar a que la concentración de ingresos y capital llene las necesidades de los globalizantes para que comience a rebalsarse a gotas, según los criterios de la nueva vanguardia! ¡Todo y todos deben sacrificarse en el altar de la globalización para responder a lo que es moderno!

Lo dicho es en alguna medida una caricatura que no hace total justicia a una cierta complejidad en los pensamientos y prácticas comparados, pero tememos que no esté tan alejada de la realidad. Si la dictadura del proletariado no fue una respuesta adecuada a las necesidades de desarrollo con justicia social, ahora nos da la impresión de que estos nuevos fanatismos han mostrado rápidamente sus límites como guías de un desarrollo moderno. Los hechos parecen mostrar que los 'neoliberalismos reales' son diversos, y que cuando tienen éxito están muy alejados de las recetas simplistas y dogmáticas. Para nosotros, una reflexión seria y profunda de estos temas es indispensable, y debemos llevarla a los más amplios espacios posibles (Co-Latino, 7 de febrero de 1997, p. 15).

$\mathrm{Ni}$ en broma, ni en serio, Héctor Dada nos ilumina agudamente para entender la verdad polarizada.

\section{El regreso del "mercader"}

En la época del mercantilismo, en los siglos XVI y XVII, se inicio un cierto proceso de globalización con la penetración geográfica y con la apropiación y expropiación de las colonias de ultramar. El símbolo del éxito económico era el oro y el superávit en la balanza de pagos. Se constituyen las naciones como estados internos y sobre todo como im- perios en competitividad. Algo así como el head to head de Lester Thurow y de nuestras trilaterales. Ćn ese proceso de mundialización pierden importancia el caballero y el guerrero del medioevo feudal y emerge el gran personaje de la época, el "mercader", que tendrá todo el apoyó de la corte. También se sacrifica el mercado interno en aras del superávit internacional.

Parecería que al finalizar el siglo XX se desarrolla un proceso similar, sólo que en clave mayor. Con el fin de la guerra fría y de las guerras calientes no es que se hayan puesto límites a los aún ingentes gastos militares y persisten los "caballeros" que se lucran con el incontrolado tráfico de armas; incluso presiden el Consejo de Seguridad de la Organización de las Naciones Unidas. De todas formas, las grandes potencias se ven llamadas a realizar transferencias de la producción bélica a la producción civil; también la tecnología realiza similar transferencia. Si disminuye la confrontación bélica aumenta la agresividad económica y con ello pasamos de la guerra-fría a la paz violenta, bajo la égida o simbiosis del mercado y del mercader. El guerrero no desaparece, solamente cambia el uniforme militar por el vestuario civil. También ahora la flota armada acompaña y protege a las galeras mercantes. Esto es sólo una parábola o una alegoría.

Como se indica en el documento que sirve de base al presente comentario, oponerse a la concepción económica neoliberal no significa en modo alguno rechazar los avances de la ciencia econó- 
mica y la utilización eficiente de los recursos de que dispone la sociedad. El siglo $\mathrm{XX}$ ha sido una gran escuela de aprendizaje y de aplicación de variadas, a veces opuestas, y evolucionantes teorías económicas. La prueba de la vigencia de tantas escuelas es que no podemos desprendernos de sus principios y enfoques pragmáticos, de suerte que al terminar el siglo las nostalgias del pasado se traducen en una proliferación de "NEOS": neo-clásicos, neo-liberales, neo-keynesianos, neo-socialistas, neo-estructuralistas, y también los neo-fundamentalistas que dan miedo. Tal vez iniciemos el tercer milenio con retazos del ya cansado siglo XX.

Economistas por aficción o dedicación entendemos que la economía es una ciencia importante, siempre lo ha sido, y su importancia nace de ser una ciencia social, al servicio de los seres humanos. Por eso rechazamos la pretensión economicista que pretende reducir el sentido de toda y de todas las vidas humanas al intercambio mercantil. Con razón, el humanismo y la humanidad se sublevan contra esta radicalización del mercado, contra esta pretensión de construir una economía antipátiça.

El neoliberalismo tal como se entiende en América Latina es una concepción radical del capitalismo que tiende a absolutizar el mercado hasta convertirlo en el medio, el método y el fin de todo comportamiento humano, inteligente y racional. Según esta concepción están subordinados al mercado la vida de las personas, el comportamiento de las sociedades y la política de los gobiernos. Este mercado absoluto no acepta regulación en ningún campo. Es libre, sin restricciones financieras, laborales, tecnológicas o administrativas...

Oponerse al neoliberalismo significa más bien afirmar que no hay instituciones absolutas para explicar o para conducir la vida humana. Que el hombre y la mujer son irreductibles al mercado, al Estado o a cualquier otro poder o institución que quiera imponerse como totalizante. $Y$ significa denunciar las ideologías totalitarias porque cuando éstas se han impuesto el resultado ha sido la injusticia, la exclusión y la violencia.

El neoliberalismo debe recordar una lección del siglo XX: que no se han tolerado ni el imperio del mercado liberal, ni el imperio colonial, ni el imperio nacional socialista, ni el imperio soviético comunista. Mantener la radicalidad de imperio es adelantar el "fin de su historia".

\subsection{Anverso y reverso}

El texto de los superiores regionales de la Compañía de Jesús reconoce elementos y efectos positivos en este proceso neoliberal.

No se nos escapan los elementos positivos de la movilización internacional llevada a cabo por las transformaciones tecnológicas que han permitido disminuir las enfermedades, facilitar las comunicaciones, acrecentar el tiempo disponible para el ocio y la vida interior, hacer más cómoda la vida de los hogares... Estas medidas de ajuste han tenido aportes positivos como la contribución de los mecanismos de mercado para elevar la oferta de bienes de mejor calidad y precios, la reducción de la inflación en todo el continente, el quitar a los gobiernos tareas que no les competen para darles oportunidad de dedicarse, si quieren, al bien común; la conciencia generalizada de austeridad fiscal que lleva a utilizar mejor los recursos públicos, y el avance de las relaciones comerciales entre nuestras naciones... Sin embargo, este proceso globalizante está generando una doble serie de desconciertos sociales, y una vez más El Salvador es un ejemplo típico.

Pero estos elementos están lejos de compensar los inmensos desequilibrios y perturbaciones que causa el neoliberalismo en términos de multiplicación de masas urbanas sin trabajo o que subsisten en empleos inestables y poco productivos; quiebras de miles de pequeñas y medianas empresas, destrucción y desplazamiento forzado de poblaciones indígenas y campesinas; expansión del narcotráfico basada en sectores rurales cuyos productos tradicionales quedan fuera de competencia; desaparición de la seguridad alimentaria; aumento de la criminalidad, empujada no pocas veces por el hambre; desestabilización de las economías nacionales por los flujos libres de la especulación internacional; desajustes en comunidades locales por proyectos de multinacionales que prescinden de los pobladores. No menos importantes son los efectos humanos que refuerzan la insolidaridad.

Pero igualmente vemos, los aspectos de estos procesos que disminuyen al hombre y a la mujer, particularmente en el contexto de la radicalización neoliberal, porque - pretendiéndolo o no- desatan la carrera por poseer y consumir, exacerban el individualismo y la competencia, llevan al olvido de la comunidad y producen la destrucción de la integridad de la creación. 
Esta impresión que recogen estos superiores latinoamericanos aparece vívidamente reflejada en la entrevista que el arzobispo de París, Mons. Jean Marie Lustiger, concediera a la revista Idées, como un reflejo de la experiencia europea ( $E C A$, 1996, p. 582).

\section{2. ¿De qué mercado nos hablan?}

Si a mediados del pasado siglo un reconocido autor nos explicaba que el mercado era el lugar de la expropiación de un plusvalor generado por el trabajo, con el advenimiento de la fase superior del capitalismo el mercado se ha convertido en un medio de exclusión del trabajo. Frente a las crecientes masas de los desempleados crónicos resultaría hoy día un cierto privilegio el tener un trabajo gravado con el IVA de la plusvalía extraida. Se trata del problema mundial del crecimiento con desempleo, de que nos habla la cumbre de $\mathrm{Co}$ penhague $y$ de un fantasma que recorre el mundo: el desempleo. Si en 1970 nos sorprendió (y a Keynes le hubiera sorprendido) la aparición de la estanflación, alza de precios con recesión económica, dos décadas más tarde, alarma la nueva enfermedad del crecimiento con desempleo. Esto significa que en la moderna economía hay ganadores y hay más perdedores.

Como todo tipo de relación, el mercado puede ser empleado perversamente para destruir a las personas y los pueblos. Pero el hecho de que pueda darse esta perversión no puede llevarnos a olvidar el patrimonio de conocimiento y de cultura que en torno al mercado ha hecho la humanidad en su historia. El desafío no es destruir la relación de intercambio, sino ponerla al servicio de la realización del ser humano en armonía con la creación, colocarla dentro de un marco de condiciones de igualdad, de oportunidades básicas para todas las personas y dignificarla, liberándola de las fuerzas de dominación y explotación que llegaron a tergiversarla en el modo de producción que se generó en occidente.

Este párrafo dice cosas más concretas de las que parece decir a primera vista. En nuestros países, tanto los gobiernos como algunos sectores empresariales afirman que el eje rector de la eco- nomía es el mercado, pero no nos explican a qué mercado se refieren, cuál y cómo es nuestro mercado. Afirmaciones como las leyes de la oferta y la demanda no sirven para detallar o describir la estructura de nuestros mercados. Necesitamos algo más concreto. Renunciar a hacer planes' de desarrollo es otra escapatoria más para renunciar a decir cómo son nuestros mercado. Valuar y evaluar la eficiencia de una economía por la evolución del producto interno bruto, la inflación y las remesas internacionales netas es una nueva intentona por cegar el conocimiento de los mercados de donde nacen el producto interno bruto, la inflación y las remesas internacionales netas. Se idolatra al mercado y tomamos todas las medidas posibles para no analizar al ídolo. Tampoco los organismos internacionales parecen interesados en que conozcamos la intimidad de este caballo de Troya.

Digamos para comenzar que el mercado es la integración de muchos mercados. Todos sabemos, aunque los neoliberales lo silencian, que el mercado no ha sido por sí sólo el mejor regulador de la evolución económica. Por ello, desde la década de 1920 se hacen análisis serios para desentrañar los mercados componentes del gran mercado. El ensayo nació en la Unión de Repúblicas Socialistas Soviéticas (sistema de balances y eslabones) y el fruto se recogió en Harvard: las matrices intersectoriales de W. Leontief. El invento se propagó a todas las naciones, de cualquier color ideológico, porque las matrices tienen una aplicación universal, igual que la aspirina. En este mapa de sectores interrelacionados $e$ interdependientes, dentro y fuera de la nación, encontramos una cercana descripción de todos los mercados: el mercado de insumos o consumo intermedio, del trabajo y de la seguridad social, de las importaciones y exportaciones, del dinero, del crédito y de la inversión, del aporte económico del Estado y por supuesto el detalle del consumo final.

Nuestro Banco Central, siguiendo un condicionamiento mundial, ha elaborado dos veces las matrices insumo-producto del país, con ayuda técnica externa y notable costo interno. Todavía está reciente la matriz de 1990, publicada en 1993. Da 
pena decir que el primero que no ha dado muestras públicas de utilizarla para conocer la estructura de nuestros mercados ha sido el mismo Banco Central y lo imitan el resto de las instituciones oficiales. Ni en el programa monetario financiero, ni en los esquemas de planes de desarrollo aparece una referencia a este instrumento de contabilidad nacional. Los sectores empresariales solicitan del gobierno el apoyo de políticas sectoriales y, al parecer, ni el gobierno ni algunos sectores empresariales conocen que pueden utilizar este radar económico.

Nuestra economía sufre de una insostenible "terciarización", por cierto muy fácil de observar en las matrices. Basta hacer un análisis comparativo de 1978 a 1990 y seguir la pista hasta 1996. Es decir, las matrices nos ayudarían a descubrir la gravedad de este problema, pero como el producto interno bruto crece, el gobierno anuncia que estamos bien. Los presidentes del istmo desean fortalecer las relaciones comerciales, pero no hemos escuchado que sus asesores hagan referencia a este instrumento de integración geográfica. Tampoco los bancos centrales están haciendo un nuevo esfuerzo por actualizar al presente quinquenio los datos obtenidos en 1990. Dato llamativo es que en 1997 nos despiertan con el invento del año, los clusters. Tratando de entender esas relaciones de industrias cercanas llegamos a la conclusión de que se trata de los mismos encadenamientos "río-arriba y río-abajo" de las matrices intersectoriales. Se habla de contratar y pagar sonadas cantidades a técnicos extranjeros, cuando la materia prima del tablero la tenemos en casa. Ahora sólo nos queda que los técnicos y la inversión extranjera nos vengan a decir cuáles son nuestros mercados. La lástima es que tenemos técnicos nacionales competentes para realizar estos análisis. Claro está que las matrices muestran cosas desagradables, que sería importante discutir...

Al renunciar a conocer nuestros mercados, algo propio de nuestro gobierno, se ha recurrido a la improvisación de las políticas económicas, o como lúcidamente lo expresa Héctor Dada al sigilo económico. Pero hay un problema mayor, señalado por varios institutos de investigación: con la terciarización se ha desfigurado el quehacer económico, basado antes en el trabajo y la producción, y ahora cada vez más en la especulación y la rentabilidad del corto plazo. Ha cambiado el espíritu de hacer economía, como nos lo indicarán más adelante algunos testimonios nacionales. Antes de comentar este problema a nivel nacional, conviene tener una visión continental de los efectos sociales de este juego del mercado, tal como se expresa el documento base del presente comentario.

Con la entrada del neoliberalismo se han acentuado los desajustes que produce en la sociedad la actuación del mercado, que no está bajo el control civil de la sociedad y del Estado. En efecto, al descuidar la producción de capital social, el mercado queda al servicio de los más educados, de los que poseen infraestructura y ponen las instituciones a su servicio, y de los que concentran la información. Al establecer la desregulación laboral y financiera, el mercado traslada fácilmente el valor producido hacia núcleos de acumulación nacional e internacional. En muchos casos no se ha incorporado al pueble en la producción vigorosa de valor agregado. $\mathrm{Y}$ en procesos como la maquila o la economía informal, no se ha permitido al pueblo participar de la riqueza que genera. De hecho no se ha dado un proceso de incorporación de los pobres, de los sectores populares y clases medias en las relaciones económicas de manera creciente con capacidades para retener el valor agregado por ella y superar la pobreza.

Las estadísticas que acompañan estas afirmaciones nos permiten deducir el siguiente subtítulo.

\subsection{Un mercado discriminante}

El presente párrafo viene acompañado de una nota a pie de página, nota aparecida en varias publicaciones, que se refiere a la desigualdad mundial y en ciertos aspectos refleja nuestra inequidad nacional.

Por efecto de estos mercados, el 20 por ciento de los habitantes del planeta tiene el 82.7 por ciento del ingreso mundial, mientras que el 60 por ciento de los habitantes tiene el 5.6 por ciento del ingreso mundial. Las desigualdades y restricciones de los mercados internacionales y la condición de socios desiguales le cuesta a los países en desarrollo aproximadamentre 500 mil millones de dólares anuales, cifra que es diez veces mayor de lo. que reciben como ayuda del exterior. En el mercado financiero, el 20 por ciento más pobre de la población mundial tan sólo participa del 0.2 por ciento de los préstamos internacionales de la banca comercial. El norte, con cerca de una cuarta parte de la población mundial, consume 70 por 
ciento de la energía mundial, el 75 por ciento de los metales, el 85 por ciento de la madera y el 60 por ciento de los alimentos.(Informe Desarrollo Humano, Programa de las Naciones, Unidas para el Desarrollo).

La intención, al trasladar esta cita del Programa de las Naciones Unidas para el Desarrollo, es hacer una aplicación a nuestro mercado monetario y financiero, volviendo al tema del cómo es nuestro mercado. Cuando a partir de 1940 se elaboran en todos los países las matrices insumo-producto, que nos diseñan la malla intersectorial del sector real de la producción, se elaboran conjuntamente las matrices del crédito y del flujo monetario (M.Copeland), de suerte que esta "liquidez" (M.V=P.Q) se canalice hacia los sectores más dinamizantes de la matriz, en orden a vigorizar el multiplicador de la inversión $(k=1 / 1-c)$. Tanto en 1986 como en 1993, fechas de las publicaciones de nuestras matrices, habíamos listado los sectores más dinamizantes y los que mostraban mayor capacidad exportadora (Realidad, 1994, p. 301). Esta descripción podía orientar la canalización del crédito para impulsar un crecimiento más armónico. De 1990 para acá, con el nuevo sistema de contabilidad nacional, la revista del Banco Central de Reserva, Sección IV, "Producción y Precios", registra los montos de consumo intermedio de cada una de las $\mathbf{4 4}$ ramas productivas. Ahí tenemos un indicador de posible dinamización interna que, sumado a los datos de los sectores que muestran capacidad exportadora o demandan mayor volumen de importaciones de bienes intermedios y de capital, nos ofrece el mapa o radar orientador del crédito de corto y largo plazo.

Pero la liquidez del oligopolio bancario no corre por estos cauces. Desde octubre de 1994, el Correo Económico de la Asociación Nacional de la Empresa Privada lamentaba la desviación global del crédito.

De darse un aumento en los mismos (intereses y encaje legal), los efectos sobre la inversión serían aún mayores que en la actualidad. Debe recordarse que, debido a la evolución de la economía salvadoreña, los márgenes de ganancia en actividades dedicadas a la atención del comercio y de los servicios son mayores que en el resto, lo que de por sí es un sesgo en lo que se refiere a la

dirección del crédito, en contra de actividades industriales y de producción en general, ya que su mayor período de maduración y menor margen de ganancias los vuelve menos atractivos para el sistema financiero “.(Realidad, 1995, p. 29). En forma concisa y desde su óptica económica, FUSADES recordaba el sesgo desviado de nuestra economía.

A manera de antecedentes cabe señalar que el panorama económico a fines de 1994 es positivo en términos de estabilidad de precios y de incremento real con tasas cercanas al 5 por ciento. No obstante, el incremento productivo estuvo liderado por sectores de bienes no transables, a saber: servicios, comercio y construcción. Dicho patrón de crecimiento no es sostenible en el mediano y largo plazo, porque se da con menor participación de las actividades que generan valor agregado, divisas y empleo. Estas actividades corresponden a la industria manufacturera y la agricultura, que son las bases de la estructura productiva de exportación o sea de bienes transables, que es lo que podría mantener el desarrollo sostenido, según FUSADES lo ha venido señalando (Realidad, 1995, p. 578).

Como la desintegración económica se ha ido profundizando, los sectores empresariales sugirieron al Presidente de la república integrar en su discurso del 1 de junio de 1996 algunas promesas sectoriales: "Se incrementan las líneas de crédito para apoyar y estimular a la micro y pequeña empresa. Se pone en marcha el plan integral de reactivación agropecuaria, cuyos puntos principales son: la seguridad juridica de la propiedad de la tierra, crédito oportuno y preferente a las activida- 
des agrícolas, suministro de tecnología e información de mercado, así como mejoras en la conservación de granos básicos, para una comercialización que garantice la seguridad alimentaria con precios adecuados a productores y consumidores". Luego de dedicar la octava promesa a la implementación de un programa de competitividad y modernización empresarial, anuncia la reestructuración de las políticas monetarias."Décimo. Promover una adecuada liquidez en el sistema financiero, para incrementar el crédito productivo y seguir facilitando el proceso de reducción de las tasas de interés, comisiones y cobros de servicios bancarios". De vez en cuando, los empresarios recuerdan al presidente de la república que dijo estas palabras.

Con el prolongado proceso de terciarización económica se ha ido deteriorando la oportunidad para lograr un crecimiento integrado de las ramas productivas. No se han logrado vigorizar nuestras exportaciones, puesto que la maquila no es un reflejo de la productividad ni de la demanda interna $y$, de una manera especial, hemos abandonado una economía basada en el trabajo y la producción para convertirla en un quehacer asentado en la especulación, el tiempo de espera y la rentabilidad de corto plazo. En este proceso insostenible, el oligopolio bancario ha buscado más su rentabilidad de corto plazo que la reactivación de la economía general. Las instituciones bancarias privadas tienen siempre un carácter de instituciones públicas, puesto que manejan un ahorro, no propio, sino nacional; sin embargo, sus ingentes beneficios y sus lucrativas comisiones no hacen honor a tal servicio público. Tampoco el sistema fiscal les hace justicia con los debidos impuestos. Este es un problema mundial, que grava más directamente los ingresos de la producción que las rentas especulativas y financieras.

El temor gubernamental al despegue de la inflación y la búsqueda de el reembolso de corto plazo en el sistema bancario frenan al crecimiento productivo, reforzando así las bases de la inflación, dificultando la reconversión industrial, la generación de empleo y una mayor equidad de los ingresos. Se crea así una cultura del corto plazo, del negocio fácil, cuando la sobrevivencia en el mar de la globalización se asienta en el conocimiento científico, en la inversión, en el invento y la innovación, en la mayor simbiosis de la investigación universitaria empresarial para crear ciencia y tecnología. Se selecciona la parte fácil de la modernización estatal, la privatización: los beneficios que puedan lucrarse de servicios públicos rentables, que otros fundaron con sus impuestos. Tal vez, porque no estamos preparados para la parte ardua y eficiente de la globalización: la educación masiva, el conocimiento científico, el culto a la calidad y a las normas de producción, que son la verdad empresarial. Así no entramos en la globalización, sino que somos arrollados por ella. El mercado nacional espera la llegada de la inversión extranjera y abrimos las fronteras al "regreso del mercader".

\section{El neoliberalismo y la crisis social general}

La oposición al neoliberalismo no se fundamenta sólo en la distorsión del orden económico nacional e internacional, que genera efectos y críticas similares o aun mayores a los experimentados en los años de 1930. Ahora, la crítica se revela universalmente necesaria porque su ideología, privadamente individualista y socialmente antisolidaria, está gestando una crisis social general. Se integran la crisis económica, la crisis social y la crisis de valores. El liberalismo muestra su falta de ética en las conductas perversas que genera. El documento base expone, de forma sintética, el abanico de desviaciones sociales, perceptibles a nivel del continente latinoamericano y que, de acuerdo con la cumbre de Copenhague, enferman al mundo actual. Preferimos trasladar literalmente este párrafo.

Es muy importante reflexionar sobre las relaciones entre el neoliberalismo y la crisis general de nuestras sociedades, porque percibimos que, al lado de la persistencia de la pobreza y el crecimiento de la desigualdad, viejos problemas de nuestras sociedades, que emergen de raíces premodernas y modernas, toman nueva fuerza. Estamos peligrosamente empujados por una cultura que radicaliza la ambición por poseer, acumular y consumir, y que sustituye la realización de todas las personas en comunidades participativas y solidarias por el éxito individual en los mercados.

En efecto, en todo el continente se percibe un rompimiento general de las sociedades que tienen múltiples causas y aparece en la inestabilidad de las familias, las múltiples y crecientes formas de violencia, la discriminación contra la mujer, la destrucción del medio ambiente, la manipulación de los individuos por los medios de comunicación, el hostigamiento al campesinado y comunidades 
indígenas, el crecimiento de ciudades inhóspitas, la pérdida de legitimidad de los partidos políticos, la corrupción de los dirigentes, la privatización del Estado por grupos con poder económico, la pérdida de gobernabilidad del aparato estatal, la penetración de consumos alienantes como la droga y la pornografía, la complejidad de procesos de secularización y de búsquedas espirituales que prescinden del compromiso comunitario y de la práctica de la solidaridad.

El neoliberalismo exacerba esta crisis al llevar a la desaparición del bien común como objetivo central de la política y de la economía. El bien común es sustituido por la búsqueda del equilibrio de las fuerzas del mercado. Contrariamente al pensamiento social de la Iglesia, que considera que debe haber tanto Estado cuanto lo requiera el bien común, el neoliberalismo plantea escuetamente que lo mejor es tener menos Estado, tanto cuanto se requiera para el buen funcionamiento macroeconómico y para el impulso de los negocios privados. En este contexto desaparece como horizonte la preocupación por la calidad de vida de la población de hoy y de mañana, que antes se expresó en los llamados estados de bienestar. Al desaparecer el objetivo del bien de todos, desaparece el sentido del hogar común o público.

Por eso no se necesita cuidar de la familia como núcleo y célula de un bien común que ya no importa. La mujer pasa a ser simplemente fuerza de trabajo más barata. La naturaleza se convierte en una fuente de enriquecimiento rápido para las generaciones presentes, el campesinado en un ciudadano ineficiente, que tiene que emigrar. En este horizonte donde lo público tiende a desaparecer, los partidos políticos, como propuesta de construcción de sociedad y nación, pierden razón de ser. La competencia política y administrativa se reduce a demostrar que el candidato o el presidente es el más capaz para crear las condiciones exigidas por el juego abierto y libre de los mercados. Unos y otros subordinados a programas de ajuste y apertura, impuestos por las mismas necesidades internacionales de los mercados. No es de extrañar que, en este contexto, donde la comunidad es irrelevante y el bien común inútil, la violencia se acreciente, la producción y el consumo de droga se disparen, y se refuercen los elementos más contrarios a la realización humana contenidos en la cultura actual, mientras se dejan de lado los aportes más valiosos de la modernidad y postmodernidad.

\subsection{El estudio del neoliberalismo}

Esta distorsión continental y también mundial de valores y conductas sociales nos exige una respuesta activa multisectorial y pluridisciplinar. El primer paso será el estudio del neoliberalismo, su racionalidad, sus supuestos éticos, sus raíces antropológicas, filosóficas, económicas, históricas; su ética y sus efectos en las personas, instituciones, comunidades y en quienes toman las decisiones políticas, que generan estos efectos devastadores. El documento señala dos grandes objetivos: superar la exclusión social que se profundiza en la economía de mercado y superar la cultura de la pobreza, entendiendo aquí esta expresión como el comportamiento de una sociedad que, en sus cuadros directivos, en sus instituciones sociales, políticas, educativas y religiosas, y en sus pobladores populares, se ha acostumbrado a vivir con la pobreza como algo normal. Aunque se tengan los medios para superar esta situación, no hay interés para ponerlos en práctica.

Encajaría aquí una tesis muchas veces repetida por Ignaclo Ellacuría, de acuerdo con la memoria fiel de uno de sus discípulos, Aquiles Montoya.

Existe un planteamiento suyo que siempre nos ha parecido una crítica al capitalismo incluso mucho más radical que la del mismo Marx. Sostenía Ellacu que el capitalismo no era universalizable por ser imposible y por ser, adicionalmente, indeseable. Tal forma de ver la realidad es sencillamente profunda. Con Marx aprendimos que lo que de un lado es riqueza y opulencia en el otro es miseria y degradación humana. Con los teóricos de la dependencia entendimos que si existen países desarrollados es porque los hay subdesarrollados. Con los ambientalistas hemos venido a profundizar aquello que decía Ellacu:"si todos viviéramos como viven los del primer mundo acabaríamos con el planeta". No es posible aspirar, en un planeta finito, a un estilo de desarrollo fundamentado en los patrones occidentales de crecimiento económico indefinido.

Ahora, dada la magnitud de la miseria en el mundo, resulta evidente que el crecimiento económico no conduce al desarrollo, entendido éste como el bienestar al estilo de los países desarrollados. Hemos aprendido que la forma de producción y consumo del capitalismo no es posible para todos y que tampoco es deseable, no sólo por ser contaminante y depredadora del medio ambiente, 
sino porque tal forma de vida consumista no humaniza ni hace felices a las personas. Para la humanidad no existe futuro si seguimos marchando por la senda del desarrollo industrial generada por el capitalismo. Por tal razón, Ignacio Ellacuría proponía la civilización de la pobreza, por oposición a la de la riqueza, la del trabajo por oposición a la del capital...(ECA, 1996, p. 1050).

El neoliberalismo no es universalizable por ser económicamente imposible y éticamente indeseable; es decir, nos queda una gran tarea.

\subsection{La búsqueda de alternativas económicas viables}

Esta preocupación no es sólo latinoamericana, también los europeos miran hacia el tercer milenio desde nostalgias y experiencias reales del siglo $X X$. En pasados artículos nos hemos hecho eco de algunas de estas aspiraciones. Están los defensores de la economía social de mercado, a la alemana y no la adulterada de algunos gobiernos nacionales, que le pegan, a modo de adorno navideño, el calificativo de "social" a una descarada economía de mercado sin puesto en el mercado. Ellos, los alemanes, se llaman "ordo-liberales", porque lo social es lo que ordena el juego del mercado. La experiencia económica alemana y su espíritu se alimenta en la enseñanza social de la Iglesia. Ellos creen, razonablemente, que esta inspiración social debe animar la búsqueda de alternativas económicas viables. "En la medida en que esto no se logra, o sea, en la medida en que los hombres viven en denigrante pobreza o que se les deban repartir los bienes esenciales fuera del proceso del mercado, la economía de mercado es imperfecta y debe ser complementada a través de la política social". Para estos autores, "el mercado no es un juego", como lo quiere presentar su coterráneo August von Hayek (ECA, 1996, p. 67).

En Europa occidental también recobra vigencia el espíritu del Estado de bienestar, integrando un neo-keynesianismo actualizado con los ideales de libertad, igualdad y fraternidad o solidaridad ( $E C A$, 1996, p. 67 y 1996, p. 865). En Europa del este, luego de un pasado totalitario $y$ ante un presente imprevisible, prosigue la búsqueda de un neo-socialismo de rostro humano ("For a humane economic democracy", Ota Sick. ECA, 1996, p. 570). No son éstas las únicas alternativas económicas viables ante el proceso de globalización.

Como lo recordaba un editorial de ECA (1996, p. 553) nunca se habían presentado a un diálogo abierto tantas propuestas de revisión económica, incluso desde el mismo sector empresarial (ANEP) como en 1996. Les dedicamos un breve comentario ( $E C A, 1996$, p. 877 ), tratando de hacernos eco de estas propuestas de diálogo. Pero ya nos explicó Héctor Dada el misterio de la exclusión en su análisis de la dictadura del empresariado. Sin embargo, el documento de los superiores regionales nos anima a esta tarea porque se trata de un clamor continental y multidisciplinario. Incluso nos ofrece una agenda de trabajo que combina la diversidad académica con la cultura ć́vica y política y el sentimiento de solidaridad con las mayorías. Como puntos de agenda no ofrecen mayor novedad, puesto que aparecen en las agendas de las propuestas nacionales, en las preocupaciones de algunas universidades e institutos de investigación. La verdadera novedad es que se trata de una búsqueda a nivel continental.

He aquí un simple índice de los temas; los recursos naturales o seguridad ambiental; la equidad de género, punto de preocupación de las cumbres de Beijing y Conpenhague; la política rural, dados los estragos del neoliberalismo en el sector campesino continental; la política industrial, que ha dejado de ser el motor del resto de la economía y depende altamente de importaciones; la política laboral en sus múltiples vertientes del debilitamiento de la legislación laboral, competencia sobre mano de obra barata, falta de calificación profesional y ausencia de la empresa como una verdadera comunidad de trabajo, desembocando todo ello en la crisis de desempleo; la deuda externa, siempre pagable y siempre impagable, hasta el punto que Juan Pablo II solicita una notable reducción o incluso condonación, porque ella grava fuertemente el futuro de estos países.

A las alternativas económicas se suma la tarea 
de "superar la crisis de la sociedad". Es la lucha contra la atomización solicitada en la cumbre de Copenhague. Se trata de la construcción de la sociedad civil, basada en el bien común, en la construcción del espacio de lo público, como tarea de todas las comunidades de solidaridad, de las iglesias e instituciones educativas. La vigorización de la vocación política que venga a superar la crisis de gobernabilidad y a dignificar el servicio público. En un año de elecciones vemos la importancia de contribuir a la formación de los hombres y mujeres con vocación política. Si estas tareas son universales geográficamente y plurisociales en cada país, hay una institución y una tarea prioritariamente importante, "la transformación del Estado".

Al comentar las políticas neoliberales, el documento nos recuerda la serie de medidas que "restringen la intervención del Estado hasta despojarlo de la responsabilidad de garantizar los bienes mínimos que se merece todo ciudadano por ser persona". Al introducir la transformación del Estado, el documento invita a una tarea comunitaria.

Debemos contribuir a un estudio interdisciplinario que haga claridad sobre el Estado, como agente importante en un modelo alternativo de desarrollo, sostenible, equitativo y donde el ser humano sea el centro; que presente alternativas al neoliberalismo que pide que el Estado se reduzca al mínimo. Los ejemplos exitosos de desarollo hoy en día muestran una acción estatal efectiva y eficiente para priorizar objetivos y gastos, imponer restricciones y distribuir pérdidas, con un papel importante del Estado en proyectos estratégicos y el suministro adecuado de los bienes que todos merecen".

\subsection{Preocupación nacional}

Esta preocupación y este debate tiene también algo de historia en nuestro país. En 1994, con ocasión del ascenso del gobierno de ARENA, recogíamos el pensamiento de algunos institutos de investigación, bajo el título de "El gobierno en los programas de gobierno". Resumiendo las funciones adjudicadas al gobierno (sin trasladar los respectivos comentarios), el Centro de Investigaciones Tecnológicas y Científicas y el Instituto de Investigaciones Económicas y Sociales de la UCA listaban la función ordenadora y reguladora, la función integradora y lá función redistributiva, junto con el papel promotor del proceso de reconversión productiva y tecnológica. La Fundación para el Desarrollo señalaba la función de un Estado orientador-regulador, responsable en lo social, promotor de la participación y la concertación, redistribuidor de los ingresos y la riqueza, promotor de la descentralización y orientador en el marco de la inserción internacional. FUSADES, bajo el marco de la modernizacíón del Estado, le señalaba las funciones de regulador eficiente, servidor eficiente, empleador eficiente, inversionista eficiente, distribuidor (sin agregar el calificativo de eficiente) y promotor de acuerdos comerciales. Adicionalmente aparece el combate por la disminución de la pobreza, la inversión en capital humano y la priorización del gasto social (Realidad, 1994, p. 173).

Esto es una muestra de que hay una preocupación y un debate sobre la transformación del Estado, que se vigoriza a lo largo de 1996. Es claro que en este aspecto difieren las propuestas de consenso de la Fundación para el Desarrollo, el Comité Permanente del Debate Nacional, el FMNL... de la tesis presentada en el Manifiesto Salvadoreño de la Asociación Nacional de la Empresa Privada. Un breve párrafo de este manifiesto muestra la posición de este sector o de quienes dicen representar al sector.

El sector püblico tiende a manejar poco eficientemente los recursos y es miope para conocer a ciencia cierta las necesidades particulares de los ciudadanos; por ello debe regresar a su lugar y tomar el rol subsidiario que le corresponde, abriendo paso a las iniciativas de la sociedad civil para que ésta, con conocimiènto de sus verdaderas necesidades, y armada de una alta dosis de solidaridad, asuma su rol protagónico... Una vez más, insistimos en el concepto de reducir el gobierno, no en su desaparición. Un gobierno eficiente es fundamental para enfrentar la deuda social, focalizando el gasto público en estas áreas (pp. 16-17).

El párrafo es bastante ambiguo: no queda muy claro, de acuerdo a la historia, si la miopía gubernamental para conocer las necesidades de los ciudadanos es más propia de los gobiernos neoliberales que de los estados de bienestar. Tampoco queda claro a qué grupo de la sociedad le confieren el don de "estar armada de una alta dosis de solidaridad" para que asuma el rol protagónico. Tampoco es muy lógico afirmar que el sector público es miope y poco eficiènte en el manejo de los recursos y al mismo tiempo confiarle la tarea más difícil de enfrentar la deuda social. Una críti- 
ca más ponderada puede leerse en la editorial: "Un manifiesto a favor del cambio"(ECA, 1996, p.553). Lo importante es que a nivel nacional y continental hay preocupación y debate sobre la transformación del Estado.

\section{4. ¿Debate teológico y eclesial?}

Hace falta agregar que se ha desarrollado una teología neoliberal o neoconservadora, que lleva a la idolatría del sistema, presentando la buena noticia de salvación a favor de "minorías".

"El Dios neoconservador es un Dios de ricos, privilegiados y capaces. Ciertamente ofrece pocas afinidades con el Dios bíblico. Más bien es una tergiversación del mismo con la pretensión de suplantar al verdadero Dios. Una estrategia que continuará. Los neoconservadores disponen para ello del triunfo mundial del sistema, pero carecen de la legitimidad del evangelio". (ECA, 1996, p. 72). También se puede estar a favor del sistema, no predicando a favor pero sí guardando un silencio comprometedor, de acuerdo al refrán: "el que calla consiente". Al redactar estas líneas estaba leyendo el folleto $\mathrm{N}^{\circ} 72$, publicado por Cristianisme $i$ Justicia (Catalunia, España), dedicado a 1996: el año de la erradicación de la pobreza.

El teólogo José Ignacio González Faus cierra este encuentro con un breve epílogo: "Consideraciones cristianas intempestivas". González Faus escribe desde el tercer mundo para su primer mundo.

El medio imprescindible para erradicar la pobreza no es sólo crear más riqueza, sino que "nosotros" seamos algo menos ricos. Por eso, si quisiéramos. ser sencillamente honestos, al año de la erradicación de la pobreza debería seguirle un 'Decenio de la erradicación de los ricos', o al menos del reparto de la riqueza. En estas condiciones, la Iglesia (tan obsesionada por la inmoralidad del preservativo) debería proclamar de una vez y bien claramente que determinadas fortunas son un pecado mortal, sujeto a ex comunión, porque impiden toda la fecundidad de los bienes de la tierra, y abortan infinitas vidas que la naturaleza destino a ser humanas... También debería decir claramente que en un sistema económico como el nuestro, donde no hay nada tan sagrado que no esté sometido a las leyes del mercado (ni el cuerpo humano, ni su fuerza de trabajo, ni las mismas leyes de la naturaleza), en un sistema así, el fraude fiscal es absolutamente, mortalmente pecaminoso. Los impuestos son el pequeño instrumento débil que tiene nuestro sistema para hacer un poco de justicia y compensar la dinámica excluyente del capital.

No proclamar eso vuelve cínica a toda esa moral, llamada 'católica'(es decir, universal), de la que hemos dicho que se obsesiona con el preservativo de los sidosos, mientras se desentiende del preservativo económico que llevan puesto siempre los millonarios. Finalmente, las iglesias cristianas, que conocen la riqueza del concepto neotestamentario de 'comunión'= koinonía, deberían declarar como radicalmente insufiente una democracia de la que queda excluido el mundo de la economía. Antiguamente la economía era un campo de la política ('Economía política' se le llamaba). Hoy en día, la política se halla sumisamente sometida a los dictados de unos poderes fácticos económicos, que sólo son responsables ante sí mismos. Denunciar la falsedad de una democracia en estas condiciones puede resultar tan molesto como lo era denunciar el mito de la democracia órgánica en tiempos de la dictadura. Pero alguien tiene que hacerlo; y las iglesias deberían jugar aquí su conocida misión de 'suplencia'. Sin democracia económica, ni puede erradicarse la pobreza ni podrá haber democracia política.

González Faus recomienda al primer mundo - y también al nuestro- 'La civilización de la sobriedad compartida'.

En lugar de una civilización de la sobriedad compartida vivimos una incultura de la riqueza concentrada. Ahora bien, este tipo de estructura social genera fatalmente una civilización del miedo; y esa es una de las características dominantes de nuestro primer mundo. Tenemos miedo: a perder lo que tenemos, al infarto, al colesterol, al sida, a perder el empleo, a la depresión, a las experiencias de sinsentido, a la incomunicación, a los de fuera, a no tener todas las 'medidas' corporales o los signos de riqueza externa que le granjean a uno la aceptación de los demás que tanto necesitamos... Y es una observación de psicología elemental que el miedo suele sacar lo peor de todos los seres humanos. Nada nos vuelve tan crueles y tan inhumanos como un miedo irracional.

Quien ha vivido y conoce los parses del tercer mundo podrá testificar que aquellas son sociedades del sufrimiento, de muchísimo sufrimiento que debe ser erradicado. Pero curiosamente (y quizás 
porque allí no hay 'nada que perder') con experiencias profundas de solidaridad, de ayuda mutua y de relaciones humanas capaces de potenciar lo mejor de muchas personas. Los habitantes del tercer mundo no son por naturaleza 'mejores' que nosotros ( $\mathrm{y}$ no les hacemos un favor mitificándolos); todos los seres humanos estamos hechos de una misma pasta débil y originalmente empecatada. Pero están mucho más liberados de ese miedo que atenaza y empeora a tantos de nosotros.

Se suele decir que 'el dinero no da la felicidad pero resuelve muchos problemas'. Desgraciadamente, eso se dice como una excusa realista para justificar la acumulación de riqueza. Pero semejante consecuencia no es lógica. Lo razonable sería concluir: quedémonos con el dinero que resuelve los verdaderos problemas (de salud, educación...) y desprendámonos de todo ese dinero que no nos dará la felicidad y podría resolver muchos problemas de otros: el impresionante dinero de las armas, el de los lujos refinados e inútiles, el de la ostentación vacía, el de los fichajes obscenos y provocativos del fútbol, el de las mil comodidades inútiles, que acabarán debilitándonos y volviéndonos obesos de cuerpo y mente...

Una 'civilización de la pobreza' no quiere decir otra cosa. Y eso sí podría contribuir decisivamente a la erradicación de la pobreza.

González Faus, sin pretenderlo, nos ha hecho una buena prédica a los habitantes del tercer mundo, en la misma línea en que nos habla nuestra teología de la liberación. Jesús de Nazaret dijo: 'el que tenga oídos para oir que oiga'; y con otras palabras dijo: el que tenga boca para hablar que hable: 'predíquenlo desde los tejados'.

\section{No canonización, pero sí beatificación}

A modo de conclusión podemos decir que no es ético canonizar el ideal totalitario y excluyente que inspira a la globalización, al someter la totalidad de la vida humana al juego de un mercado donde las fuerzas son leyes. Pero también sería herético no beatificar o no decir que hay elementos positivamente éticos eh esta revolución secular. Históricamente, los avances tecnológicos (inventos e innovaciones) han venido a colmar el desfase entre necesidades crecientes y recursos productivos relativamente escasos. Si este desfase es mayor en nuestro tercer mundo, también es mayor el desafío que tienen nuestras instituciones empresariales y universitarias, los profesionales de nuestras ingenierías, de ser creadores de una ciencia y tecnología apropiada a nuestra relación hombre capital. De lo contrario, seremos sólo importadores e imitadores de una tecnología más depredadora del medio ambiente y expropiadora de más empleos. Es un valor positivamente ético el culto a las normas de calidad. En décadas pasadas se pudo ejercer la dictadura del empresariado (público y privado) con productos y servicios de mala calidad, por el hecho de estar protegidos con excesivas exenciones y aranceles, o por la estructura monopólica u oligopólica de varios sectores públicos y privados.

Es positivamente ético revolucionar la organización empresarial de acuerdo con parámetros que la conciben, no como sociedad anónima de capital, sino como sociedad de personas al servicio de otros seres humanos, porque la empresa es el segundo hogar de la familia. Y de esto hay ejemplos buenos y malos incluso en los libros que nos anuncian el siglo XXI. Es éticamente positivo que se reflexione sobre la modernización del Estado, siempre que ello sirva para que los gobiernos sean realmente nacionales y sean compañeros de la historia de sus propias naciones. Es positivamente ético que se ponga en el centro de la economía al 'capital humano', a condición de que no se pervierta la etimología de esta expresión: capital viene de caput, que significa cabeza. Y el único factor de producción que tiene cabeza, es decir dignidad y primacía es el hombre-mujer. Por ello, el elemento que crea la riqueza de las naciones es la inversión social, pública y privada. Es éticamente positivo que la globalización sacuda a los comités económicos del ejecutivo (y quizás a los partidos políticos) para que entiendan que los problemas nacionales se mueven en el largo plazo, requieren respuestas técnicas y técnicos comprometidos (no inteligencias golondrinas) y así escuchen los clamores y las propuestas que llegan desde abajo. Es éticamente positivo que se hable de manera simultánea de libertad y democracia, porque nos ayudará a inventar e innovar la simbiosis de una democracia libre con una libertad democrática.

Por último, es éticamente positivo que, al beatificar tantos elementos buenos, nos neguemos a canonizar la globalización. Porque, tanto en la beatificación de lo bueno como en la no canonización de lo perverso y excluyente, el debate sobre el neoliberalismo genera un pleno empleo o dedi- 
cación a todos los grupos profesionales y sociales de nuestro continente.

Queremos asumir con seriedad la promoción de la justicia que surge de nuestra fe y la hace más profunda, según las cambiantes necesidades de nuestros pueblos y culturas, y según las peculiaridades del momento histórico de nuestro continente. Siempre los hombres y las mujeres estarán amenazados por la codicia de la riqueza, por la ambición del poder y por la búsqueda insaciable de satisfacciones sensibles. Hoy esta amenaza se concreta en el neoliberalismo; mañana encontrará otras expresiones ideológicas y aparecerán otros ídolos. Nosotros hemos sido llamados en la Iglesia para contribuir a la liberación de nuestros hermanos y hermanas del desorden humano, y vamos a permanecer allí en esta tarea al servicio de todos, situándonos al lado de nuestros amigos los pobres, porque desde allí lo hizo nuestro amigo, el Señor Jesús. 